Journal of Management and Economic Studies

2019, 1(7): 1-5 DOI: 10.26677/TR1010.2019.203

Journal Homepage: https://www.jomaes.org

\title{
The Change of Accountant's Role in Enterprise Resource Planning (ERP) System
}

\author{
Dao Nhat Minh \\ Quy Nhon University, Viet Nam \\ Dao Quyet Thang \\ Quy Nhon University, Viet Nam
}

\begin{abstract}
Enterprise resource planning systems (ERPS) have made waves the ability of the business to make a decision, manage business resources, or provide reasonable information for people who need information about the business. Many researches have conducted about ERP and accounting in ERP environment. However, the researches about accountants and the role of accountants in ERP are still a limit. In this paper, we will discuss accountant aspect in the ERP environment. Using discussion groups and Descriptive Statistics method, we found out the effects of an ERP system on the role of accountants.
\end{abstract}

Keywords: Enterprise resource planning systems, accountant, ERP.

\section{Introduction}

ERP (Enterprise resource planning) is the system designed to enhance the business's capacity. ERP has many definitions which depend on the researcher's perspective. Davenport (1998) defines the ERP as a commercial software package that integrates all the information flowing in the financial area, accounting, human resources, supplier control, and customer management. The other researchers have their own definitions such as "ERP systems are configurable information systems packages that integrate information and information-based processes within and across functional areas in an organization" (Kumar \& Van Hillsgersberg, 2000). "One database, one application and a unified interface across the entire enterprise" (Tadjer, 1998). “ERP systems are computer-based systems designed to process an organization's transactions and facilitate integrated and real-time planning, production, and customer response" (O'Leary, 2001). However, there is not much difference between these definitions (M. Al-Mashari et al, 2003).

The ERPs were considered one of the most significant developments made in the field of information technology in the 90s. This system type became a very popular type of software in the corporate/organizational environment. ERP system brings great impact on accounting field as well as the role of accountants. It has replaced or consolidated many works of accountants. This may change the nature of their job. If the accountants in the businesses which is adopted ERP realize these changes, they can have the best preparation for their job. 
Although the number of studies about the impact of ERP on the role of accountants has grown in recent years, it's still a limit. Desormeaux (1998) concluded that ERP implementation raises the role and position of the accounting department and accountants because accountants are considered information providers and analysts for other departments after ERP implementation, not bookkeeper as it used to. But there is insufficient data in this aspect of accounting in ERP environment. So it is difficult to draw any conclusions on this matter. Therefore, it is important for us to explore how the ERP system affects the role of accountants. Using literature review; discussion groups method with Interviewees are the experts in theory and practical ERP; and Descriptive Statistics with about 300 samples, we found out the changes in the role of accountants in the ERP environment.

\section{Literature Review}

Many researches about ERP have conducted from the 2000s which cause too many efforts to conduct an overall review. In one research attempting to make a whole picture about the researches about ERP, Tingting Huang and Kazuhiko Yasuda (2016) suggested some gaps and future trends in studies about ERP can be recognized. First, the research on SMEs will continuously increase. Many new ERP vendors especially in developing countries are providing more and more economical product that can be easily implemented and maintained by SMEs. The potential shorter life cycle in SMEs makes them better samples to address more operating issues. Second, research focused on a certain industry is insufficient. Management in the different industry varies a lot, so are the ERP systems that adopted by organizations in a different industry. Third, research on adopting the different types of ERP can be paid more attention to. New types of ERP with distinctive features are certainly emerging every year. On the contrary, research on this topic is hard to find.

This two authors also indicated what is happening and will happen in the post-implementation phase, especially, in the retire stage, needs more efforts to be found out. Quality data about utilization, transformation, replacement, etc., in organizations should be focused on as well as accumulation of long-term data in one particular organization. Since the longest time in ERP implementation course is the post-implementation period, there must be enormous issues that we have not been aware of. Specifically, differences also will generate from distinguishing industry, nation, scope, etc. The new type of ERP is thriving; however, very little empirical research.

About the impact of ERP system on accountants, all studies have confirmed the implementation of ERP will change the role of accountants. The relationship between the accountant and technology such as ERP systems shows connected together (Mike Newman and Chris Westrup, 2005). The accountant has been changed due to the implementation of ERP, from a traditional role (focus on accounting activities) to a higher role that are consultants and analysts (Scapens and Jazayeri, 2003). However, different accountant positions, the change will be different. In particular, the biggest change is in the management accountant and personnel of internal control. The role of the financial accountant will not change much (Hsueh-Ju Chen et al, 2011). Ariela Caglio (2003) also said that implementation of the ERP system will lead to the emergence of a new position "hybrid accountant" - is a combination of the accountant and other professional groups. In the environment of ERP, the management accountant has not only the accounting expertise, knowledge about the business and operational processes of the organization, but also must prepare themselves with the skills needed to meet the demand of work in the new context as communication skills to explain the results of the analysis with the management, influencing and persuading managers, IT skills to use the ERP system in the best way (Sayed, 2006). The research in this is of ERP mainly use qualitative methods. 


\section{Research design}

After the literature review, we will use the group discussion to determine the impact of the ERP system to the role of accountant through the share of views. The group discussion is used because (1) allowing many participants to involve in; (2) creating an interactive environment: discussion and debate help develop new ideas, providing detailed information for the aspects of the matter.

The Samples was selected for the group discussion is a theoretical sample. The theoretical sampling procedure was conducted by selecting each object studied until the saturation point is reached. The paper is expected to perform group discussion with: (1) the researcher in ERP field (2) ERP system's consultants and vendors, (3) the chief accountant or manager in firms using ERP. This is the group of people has solid expertise or practical experience of ERP systems. The discussion group will stop collecting data when reaching saturation or tipping point, that is meaning at this point, there is no more new information to continue for the next discussion. 9 experts were selected to participate in the group.

The quantitative method is used after the group discussion is done. The purpose of this step is to confirm what is found in the qualitative method. The sample is about 300 accountants in the Viet Nam firms which adopted ERP system over 1 year. Descriptive Statistics of the quantitative method is used.

\section{Research results and analysis}

The result of the group discussion discovered three impacts of ERP system on accountants, it included:

ROLE1: ERP system enhances the role of accountants in the firms, from the bookkeeper to consultants and analysts.

ROLE2: ERP system creates the tight connection of the accountants in professional activities.

ROLE3: ERP system links accountants' activities with other relevant modules throughout the company.

Descriptive Statistics is used in the next step to confirm what found out in the group discussion. The questionnaire sent through Google form, mail or face to face. A total of 300 questionnaires were sent, after collecting and checking, the 18 votes eliminated by providing heterogeneous information, inappropriate firm to participate in a survey or do not reply enough number of questions. Thus, the final sample was 282 units.

The majority of respondents is the chief accountant (78\%), the others are directors $(22 \%)$. Experience in using ERP systems of respondents is all over 3 years. The portion of gender is male $(65 \%)$, women (35\%). The Age over 30 is a large proportion of $80 \%$, under 30 is $20 \%$.

Table 1. Statistic of basic information

\begin{tabular}{|c|c|c|}
\hline Category & Portion & \\
\hline Position & $78 \%$ & $\begin{array}{c}\text { The chief accountant } \\
\text { Director }\end{array}$ \\
\hline $\begin{array}{c}\text { Experience in using ERP } \\
\text { systems }\end{array}$ & $100 \%$ & $>3$ years \\
\hline Gender & $65 \%$ & Male \\
& $35 \%$ & Female \\
\hline Age & $80 \%$ & $>30$ \\
& $20 \%$ & $<=30$ \\
\hline
\end{tabular}


Table 2. Descriptive Statistics

\begin{tabular}{|c|c|c|}
\hline & Mean & Std. Deviation \\
\cline { 2 - 3 } & Statistic & Statistic \\
\hline ROLE1 & 3,33 &, 736 \\
\hline ROLE2 & 3,33 &, 751 \\
\hline ROLE3 & 3,29 &, 745 \\
\hline
\end{tabular}

Table 2 shows us Mean and Std. Deviation of three impacts of ERP system on accountants. Mean of three impacts is all higher than 3, this shows the extent of the consensus of respondents about the impact of ERP system on accountants quite high. Std. Deviation, the criteria used to consider the difference of the value of each observation compared with the average value, also are in the range from 0.6 to 0.7 . Therefore, we can see the range of the observed variables in the scale is not large, in other words, the value of the survey is stable.

So we can conclude ERP system affect the role of accountants 3 aspects: enhancing the role of accountants in the firms, creating the tight connection of the accountants in firms and linking accountants' activities with other relevant modules throughout the company.

\section{Conclusion}

As ERP implementation begins, IT replaces highly repeated traditional accounting operations. Under successful ERP implementations, data quality increases, decision making is improved, and the percentage of reports automatically generated by the ERP system is greater than under the traditional ISs. Many reports produced automatically by ERP system were previously prepared by the accountants using other software, such as spreadsheets. Therefore, besides compiling data and preparing financial statements, accountants need to enhance communication and analytical ability and to familiarize with working processes in the company. Because of the complete records of transactions and clear audit trail of ERP systems, accountants can utilize the drill down function to track down every transaction in order of general ledgers, sub ledgers and transactions to improve the auditing of the company. This will strengthen its internal control to reinforce its corporate governance. After ERP implementation, the focus of internal control has shifted from accounting operation to the whole business operations. Traditional auditing emphasizes on the results such as signature and documentation instead of the causes. While the whole business auditing stresses on processes and procedures. Accountants play critical roles on effectively promoting business core value.

This paper helps accountants realize the impact of ERP system on accountants, so they can be aware of what kind of skill they need to have after ERP implementation. The research limitation of this paper is the data we obtained are mainly from Binh Dinh province, Viet Nam. Therefore, we are unable to consider the effects of ERP system on accountants in larger regions in Viet Nam such as: Ho Chi Minh City, Ha Noi, or Da Nang....We suggest future study expand the sampling scope and compare the difference in different industries and regions. 


\section{References}

Al-Mashari, M., Al-Mudimigh, A., \& Zairi, M. (2003). Enterprise resource planning: A taxonomy of critical factors. European journal of operational research, 146(2), 352-364.

Caglio, A. (2003). Enterprise resource planning systems and accountants: towards hybridization?. European Accounting Review, 12(1), 123-153.

Chen, H. J., Yan Huang, S., Chiu, A. A., \& Pai, F. C. (2012). The ERP system impact on the role of accountants. Industrial Management \& Data Systems, 112(1), 83-101.

Davenport, T. H. (2000). Mission critical: Realizing the promise of enterprise systems. Harvard Business Press.

Desormeaux, D. (1998). New world order. CMA Magazine, 72(8), 29-33.

Hsu, K., Sylvestre, J., \& Sayed, E. N. (2006). Avoiding ERP pitfalls. Journal of Corporate Accounting \& Finance, 17(4), 67-74.

Huang, T., \& Yasuda, K. (2016). Comprehensive review of literature survey articles on ERP. Business Process Management Journal, 22(1), 2-32.

Kumar, K., \& Van Hillegersberg, J. (2000). ERP experiences and evolution. Communications of the ACM, 43(4), 22-22.

Newman, M., \& Westrup, C. (2005). Making ERPs work: accountants and the introduction of ERP systems. European Journal of Information Systems, 14(3), 258-272.

O'Leary, D. E. (2000). Enterprise resource planning systems: systems, life cycle, electronic commerce, and risk. Cambridge university press.

Scapens, R. W., \& Jazayeri, M. (2003). ERP systems and management accounting change: opportunities or impacts? A research note. European accounting review, 12(1), 201-233.

Tadjer, R. (1998). Enterprise resource planning. Internetweek, (710), 40-41. 